ISSN 1518-3483

Licenciado sob uma Licença Creative Commons

\title{
A democratização do acesso à educação superior no Brasil
}

\section{The democratization of access to higher education in brazil}

\section{Sirley Terezinha Filipak, Eduardo Felipe Hennerich Pacheco*}

[a] Pontifícia Universidade Católica do Paraná (PUCPR), Curitiba, PR, Brasil

\section{Resumo}

O presente artigo tem como objetivo discutir a temática da democratização do acesso à educação superior no Brasil com base na atual configuração desse nível de ensino. Tendo em vista a complexidade da temática, optou-se em discutir a democratização da educação superior brasileira a partir dos dados divulgados pelo Instituto Nacional de Estudos e Pesquisas Educacionais Anísio Teixeira (INEP) e analisar se a meta 12 do Plano Nacional de Educação (PNE 2014-2024) poderá ser atendida no período proposto. A metodologia da análise se orientou na pesquisa documental e bibliográfica. Os resultados apontam que, historicamente, a Educação Superior foi privilégio de uma elite detentora de um poder político e econômico e que, apesar de na contemporaneidade existirem políticas públicas educacionais, de ações afirmativas e que objetivam a democratização desse nível de ensino, os números ainda são insuficientes considerando o total da população brasileira que 
possui a idade entre 18 a 24 anos. A democratização do acesso à educação superior deve ser considerada um tema indispensável na agenda política do país, sobretudo se levarmos em conta o cenário de construção da chamada "sociedade do conhecimento" e, ainda, as mudanças do mundo de trabalho, o processo de mundialização do capital e as alterações que vêm ocorrendo no papel do Estado. Garantir o acesso, a permanência e o êxito acadêmico dos estudantes devem ser considerados aspectos indispensáveis para a construção de uma sociedade mais justa, igualitária e democrática.

Palavras-chave: Democratização. Educação Superior. Plano Nacional de Educação. Permanência e Evasão.

\section{Abstract}

This article discusses the democratization of access to higher education in Brazil based on the actual configuration of this level of education. Taking into account the complexity of this subject, we chose to discuss the democratization of higher education in Brazil based on data disclosed by the Institute of Educational Studies and Research Anísio Teixeira (INEP) and analyzed whether Goal Number 12 of the National Education Plan (PNE 2014-2024) can be met within the proposed period. Documentary and bibliographical research guided the methodology of the analysis. The results point out that historically higher education was the privilege of the elites holding political and economic power. Although there are currently public educational policies with affirmative action intended to democratize this level of education, they remain insufficient relative to the total Brazilian population aged 18 to 24 years. The democratization of access to higher education must be considered an essential item of the country's political agenda, especially if we take into account efforts to build a so-called "knowledge society" and the changes in the work environment, the process of capital globalization, and the changes occurring in the role of the state. Ensuring the access, retention, and academic success of students must be considered key aspects of building a fairer, more equal, and democratic society.

Keywords: Democratization. Higher Education. National Education Plan. Permanence and Evasion. 


\section{Introdução}

Historicamente, a educação superior no Brasil é recente se comparada com os países europeus e, até mesmo, se comparada com países da América Latina. A forte resistência de Portugal em criar níveis superiores de educação em suas colônias e o imaginário coletivo da elite brasileira acerca da influência e proeminência da educação superior europeia fez com que a universidade brasileira fosse uma criação recente do século XX (CUNHA, 2000).

O presente artigo tem como objetivo discutir as possibilidades de democratização do acesso à educação superior no Brasil, com base na atual configuração desse nível de ensino. Considerando a complexidade da temática, optou-se em discutir a democratização da educação superior brasileira, bem como a permanência e a evasão dos estudantes, a partir dos dados divulgados pelo Instituto Nacional de Estudos e Pesquisas Educacionais Anísio Teixeira (INEP) e analisar se a meta 12 do Plano Nacional de Educação (PNE 2014-2024) poderá ser atendida no período proposto.

O Plano Nacional de Educação (PNE 2014-2024) foi aprovado pela Lei n. ${ }^{\circ} 13.005$ no dia 25 de junho de 2014 (BRASIL, 2014), pela então Presidente da República, Dilma Rousseff. A aprovação do PNE decenal está previsto no artigo 9. ${ }^{\circ}$ da Lei n. ${ }^{\circ} 9.394$ de 1996, que estabelece as Diretrizes e Bases da Educação Nacional (BRASIL, 1996).

O PNE (2014-2024) contempla 20 metas e estratégias que determinam diretrizes para a política educacional dos próximos dez anos. Duas metas específicas do PNE tratam da educação superior brasileira e uma meta para a pós-graduação Stricto Sensu. Sobre o acesso à educação superior, a meta 12 prevê a elevação da "taxa de matrícula na educação superior para 50\% (cinquenta por cento) e a taxa líquida para 33\% (trinta e três por cento) da população de 18 (dezoito) a 24 (vinte e quatro) anos" assegurando a "qualidade da oferta e expansão para, pelo menos, $40 \%$ (quarenta por cento) das novas matrículas, no segmento público" (BRASIL, 2014). 
Todavia, mesmo com a aprovação do PNE e com o compromisso do Governo Federal em democratizar esse nível de ensino, tão relegado às amplas camadas populacionais, a educação superior está longe de ser democratizada.

A temática do acesso do estudante à educação superior deve ser entendida de maneira intimamente ligada à problemática da permanência e evasão, pois não basta garantir apenas a democratização do acesso. As políticas públicas educacionais devem garantir o acesso a uma educação de qualidade, que tenha relevância social, e que os estudantes tenham êxito na conclusão dos estudos. E isso implica um forte investimento financeiro e cultural, no sentido de valorização da educação desde o nível básico, para que os estudantes possam chegar ao nível superior imbuídos de elementos culturais e intelectuais que propiciem o êxito em sua graduação e na profissão escolhida.

Dessa maneira, para responder a problemática proposta e cumprir os objetivos delineados, optou-se, nesta pesquisa, por realizar um estudo documental e bibliográfico, pois a pesquisa bibliográfica constitui-se em uma "preciosa fonte de informações" (SANTOS, 2000, p. 31) e é “[...] desenvolvida com base em material já elaborado, constituído principalmente de livros e artigos científicos" (GIL, 2002, p. 44).

\section{Democratização do acesso à educação superior no Brasil}

As transformações aceleradas do processo produtivo ocorridas a partir da ascensão do capitalismo, as inúmeras novas exigências da cidadania moderna, a revolução tecnológica e dos meios de comunicação de massa e a necessidade de redescobrir e revalorizar a ética nas relações interpessoais colocam a educação diante de uma questão exigente e desafiadora, visto que as escolas e universidades são, em primeiro lugar, um espaço de troca de conhecimentos e construção de valores, no qual a democracia é o marco zero para a construção de uma sociedade justa e participativa. 
A problemática da democratização da educação superior no Brasil e as questões que a ela se relacionam são polêmicas, pois são apresentadas de pontos de vista tão diversos que nem sempre são identificáveis.

Contemporaneamente, o acesso ao nível superior educacional assume uma importância cada vez maior na sociedade, sobretudo se levarmos em conta o cenário de construção da chamada "sociedade do conhecimento" e, ainda, as mudanças do mundo de trabalho, o processo de mundialização do capital e as alterações que vem ocorrendo no papel do Estado.

A partir da aprovação da Lei de Diretrizes e Bases da Educação Nacional (LDBEN - Lei n. ${ }^{0}$ 9.394/96), a educação superior brasileira presenciou um ciclo acelerado de crescimento, ciclo esse que foi diretamente impulsionado pela diversificação dos processos seletivos de ingresso, além do tradicional e excludente vestibular, principalmente no setor privado da educação superior.

Para Silva e Sguissardi (2001), a proliferação da educação superior privada no Brasil obteve enorme sucesso porque, além de contar com investimentos públicos a educação superior privada,

[...] tornou-se uma relevante estratégia de reprodução e ampliação da classe média, importante consumidor no modelo de desenvolvimento econômico associado ao capital internacional e fonte de legitimidade do regime militar-autoritário, [...]. As faculdades isoladas, em sua maioria de natureza privada, proliferaram e possibilitaram à classe média uma via de ascensão social (SILVA; SGUISSARDI, 2001, p. 178-179).

A desigualdade social presente no país, a nítida posição por políticas neoliberais de participação mínima do Estado e a forte propaganda do ensino público como uma modalidade falida de ensino foram os fatores predominantes no cenário do crescimento exacerbado dessa educação elitista e discriminatória, visto que, por possuir uma educação básica frágil, os estudantes das escolas da rede pública de educação não conseguem vagas nas universidades públicas e recorrem a universidades privadas com a ajuda de políticas e programas governamentais como o FIES e o PROUNI. 
Esse movimento, para Sguissardi (2015, p. 871), tornou-se "um intenso processo de transformação de um direito ou 'serviço público' em 'serviço comercial' ou mercadoria, isto é, que esse não seria um processo de democratização, mas de massificação mercantil” ocasionado pelo neoliberalismo econômico.

$\mathrm{Na}$ educação, o neoliberalismo atuou reduzindo o papel do Estado e adaptando o sistema educacional às necessidades da globalização, alinhada às políticas neoliberais internacionais, à LDBEN n. ${ }^{\circ} 9.394$ de 1996, contribuiu para que a educação superior brasileira cedesse à pressão de quem realmente governa, ou seja, o mercado econômico, pois, segundo Brzezinski (2010, p. 190):

O cenário da tramitação da LDB/1996 revelou o campo de disputa ideológica entre o público e o privado, tendo como foco a relação conflitante entre a defesa da escola pública, laica, gratuita para todos e de qualidade socialmente referenciada em todos os níveis de escolarização, e o ensino privado, administrado pelos empresários que não encontraram obstáculos da sociedade política para transformar em mercadoria o direito à educação preceituado na Constituição de 1988.

Como consequência desses fatores, observa-se um crescimento substantivo de instituições de educação superior com fins lucrativos, e, com isso, uma detenção majoritária no número de matrículas de estudantes.

Todavia, apesar de um aumento expressivo de matrículas na educação superior, esse nível de ensino está longe de democratizar-se às amplas camadas populacionais e isso tem implicações em todos os setores da sociedade. $\mathrm{O}$ acesso à educação superior no Brasil não deve ser considerado um privilégio "segundo a capacidade de cada um" (BRASIL, 1996), mas, ao contrário, deve ser considerado um direito democrático a todo o cidadão brasileiro, pois "uma democracia efetiva só pode ser imaginada enquanto uma sociedade de quem é emancipado" (ADORNO, 1995, p. 141-142). 
Por democracia, entende-se a forma de governo que teve sua origem na antiga cidade grega de Atenas, que era a cidade-estado mais próspera da Grécia clássica ocidental.

Conceitualmente a democracia é precisamente a forma de governo do povo (demo, "povo"; cracia, "governo"; Governo do Povo), é o "regime que assegura a igualdade, a participação coletiva de todos na apropriação dos bens coletivamente criados" (COUTINHO, 1994, p. 20). Como tal, constitui uma das formas da tipologia clássica de governo, juntamente com a monarquia (governo de um), com a aristocracia (governo dos melhores) e suas respectivas degenerações: a tirania, a oligarquia e a demagogia.

Uma satisfatória conceitualização que retomamos no presente trabalho é organizada por Zainko (2003, p. 49-50), que, apoiada nos argumentos de Marilena Chaui (2001), caracteriza democracia como "uma forma geral da existência social em que uma sociedade estabelece as relações sociais, os valores, os símbolos e o poder político", e ainda, para a autora, a democracia pressupõe os princípios de "isonomia (igualdade dos cidadãos perante a lei) e da isegoria (direitos de todos para expor em público suas opiniões, vê-las discutidas, aceitas ou recusadas em público)".

Dessa forma, como apontado pelos autores, a democratização da educação superior não pode ser confundida com massificação, "democratizar o ensino implica pensar novas formas de acesso, garantindo àqueles que chegam à universidade uma permanência com qualidade acadêmica e pertinência social" (ZAINKO, 2003, p. 54).

O fator quantitativo não é suficiente para que ocorra a democratização da educação superior; é necessário que haja a permanência do estudante e, dessa maneira, "as políticas públicas para o ensino superior devem traduzir compromissos de mudanças necessárias aos tempos atuais. Mudanças alicerçadas na democracia e na autonomia plena [...]" (ZAINKO 2003, p. 55).

Além da democratização do acesso com permanência e qualidade social da educação, as políticas para a educação superior deverão contemplar: 
Uma formação resultante de aprendizagem efetiva, relevante e pertinente. A reestruturação do fazer acadêmico articulando descentralização administração e integração institucional. A interação efetiva com os diversos segmentos da sociedade. A construção de pontes para o futuro revendo os paradigmas que norteiam as atividades acadêmicas, tanto no processo de formação envolvendo currículo, ensino-aprendizagem, avaliação, como na articulação da graduação com a pós-graduação, na produção e disseminação do conhecimento e na gestão [...] (ZAINKO, 2003, p. 55-56).

O acesso e permanência na educação superior devem ser entendidos como um importante instrumento de construção e consolidação da cidadania moderna em uma sociedade democrática. Superar essa lógica de economia de mercado que atua na educação superior e construir uma educação de qualidade social é fundamental na criação e implementação de políticas públicas educacionais, pois essa lógica mercantilista que direciona as políticas atuais faz com que, nas palavras de Antônio Joaquim Severino (2009, p. 259), a educação superior adquira "aquisição de competências não para saber fazer, mas para competir, conhecimento utilitarista, instrumental, performance competitiva. Acaba ocorrendo uma colonização da política educacional pelos imperativos da economia”.

\section{A educação superior no Brasil: indicadores}

Segundo os dados do Censo de Educação Superior elaborado pelo INEP, havia em 2015, no Brasil, 2.364 instituições de educação superior, e isso representa 4 instituições a menos que em 2014.

Das 2.364 IES em 2015, apenas 12,5\% são públicas (BRASIL, 2015). Desses dados, as Instituições Públicas Estaduais representam 40,7\% (5,1\% do total), as Federais, 36,3\% (4,5\% do total) e as Municipais, 23\% (2,9\% do total de IES públicas existentes no Brasil) (BRASIL, 2015). As Instituições de Educação Superior privadas representam 87,5\% do total de IES existentes no Brasil, sendo que a grande maioria são Faculdades 
isoladas e Faculdades Integradas, seguidas dos Centros Universitários e das Universidades (BRASIL, 2015).

Apesar de representarem apenas 8,2\% do total de instituições, as Universidades detêm $53,2 \%$ das matrículas nos cursos de graduação (BRASIL, 2015).

Nessa mesma estatística elaborada pelo INEP em 2015, foi constatado que existiam 33.501 cursos de graduação, podendo esses cursos ser de Bacharelado, Licenciatura ou Tecnólogo. Constatamos ainda, segundo o Inep/Deed, que tivemos o total de 8.027.297 de matrículas nesses cursos, representando um aumento de 2,5\% em relação ao ano de 2014 e de 75,7\% de aumento entre 2005 e 2015. Em comparação com o ano de 2014, o número de ingressos efetivos nos cursos, tanto presencial quanto a distância tiveram uma queda considerável, sendo 4,6\% nos cursos a distância e 6,6\% nos presenciais (BRASIL, 2015).

Os cursos de bacharelados ainda mantêm significativa predominância na Educação Superior e em 2015 apresentaram um crescimento de $3,9 \%$ em comparação ao ano anterior e correspondem a $68,7 \%$ do total de matrículas das IES. As Licenciaturas representam 18,3\% do total de matrículas, obtendo um crescimento de $0,4 \%$ em relação a 2014 e de $51,7 \%$ em relação ao ano de 2005. Os cursos tecnológicos tiveram um crescimento de 2,1\% em relação ao ano anterior, com um total de 43.410 matrículas, sendo que $62,6 \%$ dessas matrículas estão em cursos presenciais (BRASIL, 2015).

É interessante analisarmos três importantes dados: 1) entre os estudantes matriculados nas Instituições de Educação Superior, tanto na modalidade presencial quanto na modalidade a distância, a predominância é do sexo feminino; 2) a idade mais frequente dos estudantes matriculados é de 21 anos nos cursos de graduação presencial e de 33 anos nos cursos a distância; e 3) o turno noturno ${ }^{1}$ é o mais demandado nos cursos de graduação presencial no Brasil (BRASIL, 2015).

1 Esse dado em específico nas palavras de Oliveira e Bittar (2010, p. 12-13), revela que "a história do ensino noturno e, em particular, do ensino superior é bastante penosa no Brasil, sobretudo por duas razões: de um lado, está associada ao ideal de democratização do acesso dos estudantes 
Todavia, de acordo com os dados do Instituto Brasileiro de Geografia e Estatística (BRASIL, 2013), as matrículas na educação superior precisam dobrar até 2020, pois, segundo o Censo da Educação Superior de 2015, a taxa da população de 18 a 24 anos que frequentam a educação superior (inclusive a pós-graduação) encontra-se em 17,6\% (BRASIL, 2015), o que tem implicações para o setor público, pois requer um forte investimento na educação básica e superior para aumentar esse percentual, principalmente na rede federal de educação superior.

Segundo Corbucci (2007, p. 18):

[...] a incapacidade do poder público federal de ampliar os gastos em educação, em grande medida devido ao processo de ajuste fiscal dos anos de 1990, fez com que não conseguisse atender plenamente à crescente demanda por educação superior. Esse processo de enfraquecimento do setor público federal foi um dos elementos centrais para a forte expansão na oferta de vagas e o aumento das matriculas no setor privado, favorecidos por certa desregulamentação do setor, no que se refere à flexibilização dos requisitos para a criação de cursos e instituições.

Como observado por Corbucci (2007), o poder público, por não investir recursos suficientes na educação superior pública, promoveu um esfacelamento da expansão das IES públicas, causando, dessa maneira, um número considerado baixo de matrículas, levando em consideração a população de 18 a 24 anos presente no País. Além disso, o Brasil ainda apresenta um percentual relativamente baixo de jovens na faixa etária

trabalhadores e, de outro, está relacionada com as condições mais precárias de ensino e de aprendizagem, sobretudo em IES privadas que oferecem, em geral, cursos de qualidade bastante questionável. Além disso, essa história retrata a luta dos trabalhadores por oportunidades de estudar, mesmo trabalhando oito horas diárias ou mais. Os estudantes precisam, assim, conciliar trabalho e estudo, na maioria das vezes sem apoio financeiro do Estado, acreditando que o estudo poderá melhorar a sua condição de vida. Todavia, dado as condições objetivas, boa parte dos estudantes do ensino superior noturno, sobretudo privado, acaba se tornando inadimplentes, evadindo ou mesmo concluindo um curso em condições que não permitem agregar maior valor à formação e à qualificação para o mundo do trabalho, assim como para o desenvolvimento pessoal e preparo para o exercício da cidadania". 
de 18 a 24 anos cursando a educação superior - são apenas 3.984.707 (17,6\% do total da população nessa faixa etária). Para se ter uma ideia, em alguns países da comunidade europeia, esse percentual chega a ser de mais de $50 \%$.

Como apontado pelo Censo da Educação Superior de 2015, há um crescimento contínuo de matrículas de jovens de 18 a 24 anos, porém, esse crescimento é insuficiente para o cumprimento dos $33 \%$ da taxa líquida de matrículas na Educação Superior até 2024, previstos na meta 12 do PNE. O indicador revela que desde 2004 houve um crescimento contínuo na taxa líquida de matrículas. No entanto, nos últimos seis anos, de 2009 para 2015, o indicador avançou apenas 3,3\%, o que pode ser considerado um ritmo insuficiente para o cumprimento da meta em 2024 (BRASIL, 2015).

Outro dado relevante é que houve uma considerável queda no número de matrículas na rede pública de educação superior. Observamos que, de 2009 para 2010, o número de matrículas nos cursos de graduação na educação superior brasileira cresceu $7,1 \%$, contabilizando um crescimento de $110,1 \%$ na última década.

Esse crescimento se deu majoritariamente no setor privado da educação superior, que foi responsável por $76 \%$ do número de matrículas em 2015, ou seja, a cada 4 estudantes de graduação, 3 estudavam em instituições privadas, enquanto que, em 2014, a média era de 2,5 estudantes matriculados na rede privada para cada estudante na rede pública (BRASIL, 2015).

Em 2015, o número de matrículas nas IES privadas era de 6.075.152, e na rede pública, 1.952 .145 (24\%), totalizando, dessa maneira, a queda de matrículas de $3,5 \%$ na rede privada e uma queda de $0,5 \%$ na rede pública. Na modalidade presencial, as IES privadas detinham $72,5 \%$ do total de matrículas na graduação em 2015, e na modalidade a distância ${ }^{2}$

2 Para Lima (2004, p. 41) "desde o governo neoliberal de Fernando Henrique Cardoso a educação à distância tem sido utilizada como mais uma estratégia de privatização das universidades públicas, 'maquiada' com o discurso da democratização do acesso a esse nível de ensino". 
esta participação é ainda maior, 90,8\% (BRASIL, 2015), como resultado da necessidade de alinhar trabalho e flexibilidade de horário para estudar.

Essa configuração majoritariamente privada da educação superior brasileira "dificulta o acesso e a permanência dos jovens na educação superior, mas a ampliação da oferta de vagas muitas vezes é utilizada para levar ao entendimento de que o acesso depende tão somente de esforço individual" (GISI; PEGORINI, 2016, p. 28).

Contudo, mesmo com os números significativos, temos que levar em conta que, apesar de as matrículas na educação superior indicarem um crescimento expressivo no período de 2005 a 2015,

[...] este aumento, no entanto, não ocorre sem problemas, vem acompanhado do aumento de vagas ociosas, evasão, inadimplência e crescente diminuição da relação candidato/vaga nas instituições privadas. A evasão também se faz sentir nas instituições públicas, o que pode estar associado, entre outros fatores, à necessidade que os alunos têm de trabalhar para se manter, uma vez que a expansão de vagas em cursos noturnos naquelas instituições ainda não é suficiente para a demanda existente (BONETTI; GISI, 2007, p. 75).

Conforme apontado por Bonetti e Gisi (2007), há uma enorme diferença entre o número de matrículas e o número de concluintes. Segundo dados do Censo da educação superior (INEP, 2015), em 2015, mais de um milhão e cem mil estudantes concluíram a educação superior, ou seja, há uma diferença entre o número de matrículas e o número de concluintes, além disso, segundo o portal do MEC, "em 2010, 11,4\% dos alunos abandonaram o curso para o qual foram admitidos" e "em 2014, esse número chegou a 49\%" (PORTAL DO MEC, 2017).

Entre 2014 e 2015, o número de concluintes na rede pública diminuiu 0,8\%, já na rede privada, a variação foi de um aumento de 15,9\%. No período de 2005 a 2015, o maior aumento percentual do número de concluintes em cursos de graduação se deu na rede privada, com 72,8\%, enquanto que na pública esse crescimento foi de $17,8 \%$ no mesmo período (INEP, 2015). Em 2015, o número de concluintes em cursos de graduação 
presencial teve aumento de 9,4\% em relação a 2014, e a modalidade a distância aumentou 23,1\% no mesmo período (BRASIL,2015).

Segundo o mapa do ensino superior elaborado pelo Sindicato das Mantenedoras de Ensino Superior do Estado de São Paulo (SEMESP):

A taxa de permanência total em um curso no Brasil para o ingressante que entrou em 2010 e não se evadiu em cinco anos chegou a 51,3\% na rede pública e $40 \%$ na privada. Já a taxa de permanência nos cursos presenciais chegou a $51,6 \%$ na rede pública e $40,9 \%$ na privada. E nos cursos EAD a taxa de permanência ficou em $48,2 \%$ na rede pública e 36,2\% na privada (SEMESP, 2016).

Mais da metade dos concluintes dos cursos de graduação em 2015 estudou em universidades, seguido pelas faculdades, pelos centros universitários e pelos institutos federais de educação. O percentual de concluintes que estudaram em faculdades foi de $28,9 \%$, em centros universitários, $18,2 \%$, e apenas $1,0 \%$ dos concluintes de cursos de graduação estavam em institutos federais. O grau de "bacharelado teve o maior aumento em 2015 (12,7\%) quando comparado a 2014. Licenciatura (9,6\%) e tecnológico (12,3\%) tiveram crescimento menor" (BRASIL, 2015).

Assim, percebemos que, diante do panorama apresentado e a partir dos dados estatísticos divulgados pelo INEP, PNAD e pelo IBGE, o proposto na legislação continua muito distante da realidade, e que a meta 12 do novo Plano Nacional de Educação que propõe "elevar a taxa bruta de matrícula na educação superior para $50 \%$ e a taxa líquida para $33 \%$ da população de 18 (dezoito) a 24 (vinte e quatro) anos, assegurada a qualidade da oferta e expansão para, pelo menos, $40 \%$ das novas matrículas, no segmento público" (BRASIL, 2014) não está sendo atendida, repetindo a mesma situação do plano anterior.

Os dados não demonstram um avanço, considerando o número de jovens matriculados na educação superior, além de uma queda das matrículas na rede pública e uma monopolização de matrículas na rede privada, o que atende a interesses do capital privado e não interesses democráticos. 
Outro fator que merece atenção é que número de matrículas não significa sucesso e conclusão acadêmica, e prova disso são os números de vagas ociosas e de evasão na educação superior. O censo de 2015 aponta que, das 6,1 milhões de novas vagas em instituições públicas e privadas de educação superior, somente 42,1\% estão preenchidas, e 13,5\% das vagas remanescentes foram ocupadas. Além disso, há uma enorme taxa de desistência do curso de ingresso (BRASIL, 2015).

Os dados apresentados no presente trabalho revelam os seguintes aspectos da educação superior brasileira:

- desde seus primórdios, teve um caráter desigual de acesso, permanência e êxito acadêmico para com os estudantes menos favorecidos economicamente;

- há um considerável crescimento do setor privado da educação superior, tanto do número de matrículas de estudantes quanto um crescimento do número de instituições privadas de ensino. Esse crescimento foi influenciado e impulsionado pelas políticas afirmativas compensatórias como o PROUNI e o FIES, que investem capital econômico público em instituições privadas de ensino;

- diminuição do número de estudantes matriculados no setor público, o que indica uma forte tendência do governo em privatizar a educação superior, e isso vem ocorrendo por meio dos incentivos fiscais e uma forte propaganda do não êxito da educação pública;

- certa disparidade entre o número de ingressantes e concluintes nas instituições públicas e privadas. Desta forma, as metas do Plano Nacional de Educação (PNE 2014-2024) e os compromissos do Governo para com o movimento Todos pela Educação não estão sendo cumpridos; 
- extrema necessidade de investir em recursos humanos e financeiros em uma educação básica ${ }^{3}$ de qualidade, para que os jovens que ingressam na educação superior estejam capacitados e imbuídos de aspectos intelectuais e culturais necessários para um bom êxito acadêmico e profissional;

- não basta criar políticas públicas de acesso à educação superior aos estudantes sem levar em conta a permanência e o êxito acadêmico e profissional dos mesmos. É necessário criar mecanismos que propiciem aos estudantes que ingressam na educação superior via políticas de acesso elementos necessários para uma formação completa com relevância e qualidade social, e que contribua para o crescimento do país, diminuindo a diferença e as desigualdades sociais presentes na sociedade brasileira.

\section{Permanência e Evasão na Educação Superior Brasileira}

Como já analisado no item anterior do presente trabalho, o grande desafio que se impõe à efetiva democratização da educação superior no Brasil não é apenas o desafio do ingresso dos estudantes a esse nível de ensino, mas sua permanência e êxito em sua jornada acadêmica rumo à formatura e a garantia de entrada no mercado de trabalho.

Permanência e evasão referem-se a dois aspectos diferentes da educação superior. A palavra evasão é

3 Segundo Muniz (2002, p. 234), para que o acesso à educação superior seja de fato democrático, e "para que as desigualdades sociais sejam de fato reduzidas, é necessário que todos tenham iguais oportunidades. Ora, sabemos bem que, no âmbito educacional, as desigualdades são latentes. As escolas públicas de primeiro e segundo graus, na grande maioria, nem de longe se comparam com as escolas privadas. Os alunos que dali saem não estão preparados para enfrentar a concorrência no mundo hoje dito globalizado, sendo certo que, em razão de seu poder aquisitivo, não se achem em condições de ingressar em uma universidade pública". 
[...] utilizada na área das ciências da educação para designar a saída de indivíduos matriculados em qualquer nível do sistema educacional requer, assim, alguma precaução e exame prévio. Originalmente, a palavra é sinônimo de fuga, evitação e desvio. Seu contrário quer dizer continuar, ficar, estar cativo, aprisionado, prisioneiro. Coulon (2008) irá referir dois fenômenos diferentes: eliminação, quando os estudantes, em função de fracasso repetido ou não, interrompem o curso que fazem e abandono (autoeliminação), que ocorre por iniciativa do estudante, após um período, onde ele, sem ter atingido sua afiliação intelectual ou institucional, desiste tanto do curso como da universidade; o primeiro ano, para esse autor, é o mais crítico de todos (SANTOS; SILVA, 2011, p. 252-253).

Como apontado por Santos e Silva (2011), há uma tênue fronteira que separa a evasão e a exclusão, porém ambos os conceitos se referem à dificuldade que os estudantes que ingressam enfrentam para permanecer na educação superior. Em um estudo elaborado por Estrada e Radaelli (2014), no qual os autores realizam uma pesquisa junto aos estudantes que evadiram da educação superior, eles observaram que os principais fatores que influenciaram a evasão ou ao trancamento do curso foram:

[...] $65 \%$ por questão financeira [...], 10\% em decorrência do tempo de conclusão do curso, $3 \%$ pelo período/turno do curso, $5 \%$ por não ser o curso que desejaria seguir carreira, $2 \%$ pela visibilidade econômica que o curso proporciona, $10 \%$ por não conseguir conciliar trabalho e estudo e $5 \%$ por não conseguir auxílio da assistência estudantil (ESTRADA; RADAELLI, 2014, p. 43-44).

Em outro estudo, tipo estado da arte, elaborado por Morosini (et al., s/d), os autores identificaram oito principais motivos presentes nos trabalhos dos pesquisadores brasileiros que levam aos ingressos evadirem do ensino superior, sendo eles:

1. Aspectos financeiros relacionados à vida pessoal ou familiar do estudante; 2. Aspectos relacionados à escolha do curso, expectativas 
pregressas ao ingresso, nível de satisfação com o curso e com a universidade; 3 . Aspectos interpessoais - dificuldades de relacionamento com colegas e docentes; 4 . Aspectos relacionados com o desempenho nas disciplinas e tarefas acadêmicas - índices de aprovação, reprovação e repetência; 5. Aspectos sociais, como baixo prestígio social do curso, da profissão e da universidade elegida; 6. Incompatibilidade entre os horários de estudos com as demais atividades, como, por exemplo, o trabalho; 7. Aspectos familiares como, por exemplo, responsabilidade com filhos e dependentes, apoio familiar quanto aos estudos etc.; 8. Baixo nível de motivação e compromisso com o curso (MOROSINI et al., s/d, p. 8).

Como observado pelos estudos elaborados por Estrada e Radaelli (2014) e Morosini (et al., s/d), são inúmeras as causas que levam aos ingressos evadirem da educação superior e isso demonstra a incapacidade do Governo em implantar medidas que garantam não apenas o acesso à educação superior, mas a permanência do estudante na mesma.

Por sua vez, a permanência na educação superior refere-se especificamente ao ato, estado, condição do estudante que ingressa na educação superior concluir essa etapa formativa.

Nas análises elaboradas no presente trabalho, compreendemos que as políticas públicas educacionais como o Programa Universidade para Todos (PROUNI), o Fundo de Financiamento ao estudante do Ensino Superior (FIES), o Programa de Apoio a Planos de Reestruturação e Expansão das Universidades Federais (REUNI) e a Lei n. ${ }^{\circ} 12.711$ vêm contribuindo significativamente para o aumento do número de estudantes à educação superior. Para Gisi, Hanhart e Filipak (2015, p. 128):

A opção por políticas compensatórias e focalizadas, que buscam atender aos grupos sociais que historicamente não tiveram acesso à educação superior vem sendo uma medida de fundamental importância, por se constituir em uma possibilidade de contribuir com a diminuição das desigualdades sociais, mas, além dessas iniciativas, faz-se necessário uma política social que atenda às necessidades da população e, especificamente, uma política educacional que priorize a educação em 
sua totalidade (básica e superior) no país. São poucos os jovens dos referidos grupos que chegam ao final do ensino médio e que conseguem ingressar na educação superior. A evasão é evidente quando analisados dados de ingresso e conclusão em todos os níveis da educação no país.

Todavia, apesar da existência de políticas públicas educacionais que garantam o acesso a uma parcela da população historicamente excluída, mediante programas de bolsas e vagas na rede pública de educação superior, o número de vagas ociosas e de evasão é alarmante, e isso, para Boneti, Gisi e Filipak (2013, p. 525), significa que

[...] nem mesmo a gratuidade é critério suficiente para o preenchimento das vagas. Existem dificuldades de aprendizagem para a aprovação em processo seletivo nos cursos ofertados, pois as questões relacionadas ao acesso têm relação direta com a Educação Básica, uma vez que esta consiste em um elemento explicativo das particularidades do acesso e as possibilidades de permanência. Observam-se também dificuldades econômico-financeiras, altos índices de desistência ocasionados por diferentes causas, sendo uma dessas os projetos pedagógicos, que não contemplam a diversidade cultural.

Para Boneti e Gisi (2007, p. 79), “a permanência na educação superior pressupõe condições preexistentes, em especial capital cultural, que é adquirido ao longo da trajetória de vida escolar e que não se obtêm de um momento para o outro".

Não obstante, sabe-se, por estudos recentes, que a diferença de perfil socioeconômico dos estudantes da educação superior tem relação não somente com o tipo de instituição pública ou privada, mas inclusive com a distinção que é elaborada em relação a cursos de "maior prestígio" ou "menor prestígio" social e ao turno, diurno e noturno. E, segundo Bonetti e Gisi (2007, p. 77):

Essa desigualdade se faz sentir desde o início da educação básica, quando os alunos já chegam em condições desiguais em decorrência 
das oportunidades que tiveram ou não. Quanto menores essas oportunidades, menor capital cultural possuem. Amplia-se a possibilidade de acesso à escola básica de alunos de diferentes condições sociais, o que aparentemente demonstra um esforço de propiciar oportunidades iguais a todos, mas que continua perpetuando a desigualdades, pois o acesso ao que é considerado capital cultural é restrito aos que possuem o código que possibilita a sua aquisição.

Sem esse capital cultural mencionado por Bonetti e Gisi (2007), os estudantes chegam à educação superior completamente despreparados. Para Zago (2006, p. 233):

[...] os efeitos dessa exclusão do conhecimento aparecem com toda a força na escolha do curso, e faz-se sentir igualmente quando o estudante ingressa no ensino superior, sobretudo nas primeiras fases do curso [...]. É a mesma coisa que pegar um filme pela metade, não tem como entender inteiro.

De acordo com Ristoff (2014, p. 742-743), além dessa problemática apontada por Zago (2006), a origem social e a "situação econômica da família do estudante é, sem dúvida, um fator determinante na trajetória do jovem brasileiro pela educação superior e, por isso mesmo, deve estar na base das políticas públicas de inclusão dos grupos historicamente excluídos".

Outro fator que tem contribuído para a desistência e evasão ${ }^{4}$ na educação superior, segundo Silva (et al., 2002, p. 276), é

[...] por conta da ideia utilitarista ou materialista ligada mais à retribuição financeira da profissão do que de algum ideal [...]. Diante da situação socioeconômica da população, a qual empobrece a cada ano

4 Rosa (2014) identificou em sua pesquisa que existem três distintas modalidades de evasão, para a autora são elas: "a) evasão do curso: desligamento do curso superior em razão do abandono, o que pode ocorrer por não realização da matrícula, transferência de instituição de ensino, mudança de curso, trancamento ou exclusão por desatendimento a alguma norma institucional; b) evasão da instituição, que se caracteriza pelo desligamento da instituição na qual o aluno está matriculado; c) evasão do sistema, que configura o abandono, definitivo ou temporário, do sistema de educação superior" (ROSA, 2014, p. 247). 
que passa, e das pesadas anuidades cobradas em universidades particulares, é expressivo o número de jovens que abdicam do curso desejado por outro de custo mais baixo ou, simplesmente, abandonam seus estudos pelo emprego.

Além disso, segundo Baggi e Lopes (2011, p. 356), “são poucas as instituições que possuem um programa institucional regular de combate à evasão, com planejamento de ações, acompanhamento de resultados e coleta de experiências bem-sucedidas".

Diante dessa prerrogativa, acesso, permanência e expansão, apesar de serem processos diferentes, devem estabelecer uma relação mútua. Para Silva e Veloso (2010, p. 222);

A permanência dá sentido ao acesso, configurando a continuidade da trajetória de formação; a expansão tem relação (e impacto) com o acesso na proporção do crescimento quantitativo [...] e das suas características (ensino público/gratuito, organização acadêmica, curso, avaliação/qualidade). De igual forma, poder-se-ia mencionar outros fenômenos distintos, mas a eles articulados, como financiamento e evasão. Tais afirmações convergem para a afirmação de que o acesso não comporta uma explicação isolada ou descontextualizada.

Para que ocorra de modo efetivo a democratização da educação superior no Brasil, não é suficiente garantir apenas o acesso gratuito ao estudante; as políticas públicas educacionais devem garantir sua permanência, pois, além da mensalidade, os estudantes possuem despesas com alimentação, transporte, moradia, materiais escolares, livros, fotocópias, impressões, entre outras; ademais, muitos alunos, além de estudar, precisam trabalhar para manter essas despesas. Segundo os estudos elaborados por Bori e Durhan (2000, p. 35), “[...] existe quase uma unanimidade por parte dos estudiosos da área em considerar que o trabalho para o estudante universitário é prejudicial em termos pedagógicos".

Outra questão que contribui para a evasão dos cursos de graduação é a estrutura pedagógica que a educação superior brasileira ainda sustenta. 
Os currículos e avaliações persistem na meritocracia individual, não levando em conta a trajetória de vida do estudante. Carvalho (2004, p. 330), comentando acerca desse ponto, exprime que "para uns, a democratização se caracteriza por políticas públicas de abertura [...] para todos, para outros, ela decorre de práticas pedagógicas capazes de formar indivíduos livres".

A respeito da estrutura pedagógica que propicie a permanência e o sucesso acadêmico dos estudantes, Gisi (2006, p. 13) esclarece:

A permanência na educação superior, para os alunos mais pobres, é difícil não só pela dificuldade de pagar as mensalidades, como já foi mencionado, como pela necessidade de suporte pedagógico. Verificase que muitas instituições privadas não possuem nem mesmo bibliotecas adequadas, o que prejudica a aprendizagem e torna necessários gastos com livros e reprodução de material bibliográfico.

Com todos esses fatores mencionados,

[...] é no mínimo questionável se a expansão ocorrida no ensino superior se traduziu numa efetiva democratização do acesso, mais ainda quando se pretende estender essa democratização ao sucesso acadêmico dos estudantes (ALMEIDA et al., 2012, p. 907).

Deste modo, se pensarmos que o acesso, a permanência e o êxito acadêmico, são processos que estão intimamente relacionados, pode-se questionar se a democratização da educação superior realmente está ocorrendo no Brasil, ou se ainda é uma realidade distante, legada apenas a uma parcela da população. E se chegar a essa linha de raciocínio, entende-se que:

[...] igualdade de condições para o acesso e permanência [...]adquire o significado de uma verdadeira utopia. É necessário enfatizar que essa utópica igualdade de condições para o acesso à, e de permanência na, educação superior é, como nos demais níveis, condição básica da democratização desse nível de educação. Isto é, não se pode falar em processo de democratização sem que se verifique algum grau importante de igualdade de condições para todos os candidatos a uma vaga na educação superior (SGUISSARDI, 2015, p. 877). 
Assim, como apontado por Sguissardi (2015), a permanência constitui-se como um dos fatores primordiais para a democratização da educação, não apenas a democratização da educação superior, mas de todos os níveis educacionais. Como já mencionado, o ingresso na educação superior não é suficiente, é necessário que as políticas públicas educacionais viabilizem as condições necessárias para que os estudantes possam ter igualdade de oportunidades, sucesso e êxito acadêmico e uma formação de qualidade social, cultural, acadêmica e intelectual desde a educação básica.

\section{Considerações finais}

A temática da democratização do acesso à educação superior no Brasil é intrigante, pois percorrê-la significa perpassar por inúmeros vieses que nem sempre são claros e objetivos.

A construção do presente trabalho procurou evidenciar que o acesso à educação superior deve ser entendido como um importante instrumento de construção e consolidação de cidadania moderna em uma sociedade democrática e que, apesar de ter ocorrido mudanças significativas nos processos seletivos de ingresso, e o número de matrículas ter gradualmente aumentado, o acesso ainda é um desafio, principalmente nas instituições públicas e nos cursos que gozam de melhores status sociais, o que significa que a democratização está longe da igualdade de acesso e isso se reflete em todos os níveis da sociedade.

A Declaração Mundial sobre a Educação Superior afirma, no seu preâmbulo, que:

[...] sem uma educação superior adequada e instituições de pesquisa que formem massa crítica de pessoas qualificadas e cultas, nenhum país pode garantir genuíno desenvolvimento endógeno e sustentável e, em particular, os países em desenvolvimento e os países de menor desenvolvimento relativo não poderão reduzir o hiato que os separa dos países desenvolvidos industrializados (BERNHEIM; CHAUÍ, 2008, p. 16). 
Diante desse cenário e da análise das informações apresentadas, podemos concluir que a educação superior sempre foi destinada a uma parcela reduzida da população. Não basta garantir o acesso, pois há necessidade de criar condições para que o estudante conclua a sua formação inicial e obtenha êxito em sua vida profissional.

Ainda com o crescimento do número de instituições de ensino, de matrículas e de bolsas de estudo nos últimos anos, as metas do Plano Nacional de Educação (PNE 2014-2024) e os compromissos do Governo para com o movimento Todos pela Educação não estão sendo cumpridos.

Após o êxito no ingresso em uma instituição de educação superior, os estudantes enfrentam o fracasso, pois, ao longo do curso, por falta de condições mínimas para a continuidade dos estudos, acabam desistindo.

A desistência do curso poderia ser evitada se os estudantes tivessem o apoio necessário para a permanência e conclusão do curso escolhido, tornando realidade a democratização da educação superior.

\section{Referências}

ADORNO, Theodor. Educação e Emancipação. Rio de Janeiro, Paz e Terra, 1995.

BAGGI, Cristiane Aparecida dos Santos; LOPES, Doraci Alves. Evasão e avaliação institucional no ensino superior: uma discussão bibliográfica. In: Avaliação (RAIES - Revista da Avaliação da Educação Superior), Campinas/Sorocaba, v. 16, n. 2, p. 355374, jul. 2011. Disponível em: <http://www.scielo.br/scielo.php?script=sci_arttex t\&pid=S141440772011000200007>. Acesso em: 26 abr. 2017.

BERNHEIM, Carlos Tünnermann; CHAUÍ, Marilena de Souza. Desafios da universidade na sociedade do conhecimento: cinco anos depois da conferência mundial sobre educação superior. Brasília: UNESCO, 2008. 44p. Ed.2004/WS/11.

BONETI, Lindomar Wessler; GISI, Maria Lourdes. As desigualdades sociais e as políticas de acesso à educação superior no Brasil In: EYNG, Ana Maria; GISI, Maria Lourdes (Org.). Políticas e gestão da educação superior: desafios e perspectivas. Ijuí, RS: Editora Unijuí, 2007. 
BONETI, Lindomar Wessler; GISI, Maria Lourdes; FILIPAK, Sirley Terezinha. Do Direito à Educação Superior ao Desafio do Acesso para todos. Revista Diálogo Educacional (PUCPR. Impresso), v. 13, p. 517-536, 2013.

BORI, Carolina M.; DURHAM, Eunice R. Equidade e heterogeneidade no ensino superior brasileiro. Brasília: Instituto Nacional de Estudos e Pesquisas Educacionais, 2000.

BRASIL. Lei n. 9.394, de 20 de dezembro de 1996. Estabelece as diretrizes e bases da educação nacional. Diário Oficial [da] República Federativa do Brasil, Brasília: DF, 23 dez. 1996. Disponível em: <http://www.cpt.com.br/ldb/lei-de-diretrizes--e-bases-da-educacao-completa-interativa-e-atualizada>. Acesso em: $10 \mathrm{dez}$. 2016.

BRASIL. INEP. Apresentados resultados do Censo da Educação Superior 2015. Disponível em:< http://portal.inep.gov.br/censo-da-educacao-superior >. Acesso em: 03 mar. 2017.

BRASIL. Lei $\mathrm{n}^{\circ}$ 13.005, de 25 de junho de 2014. Aprova o Plano Nacional de Educação (PNE) e dá outras providências. Diário Oficial da União [da] República Federativa do Brasil, Brasília, 26 jun. 2014.

BRASIL. PORTAL DO MEC. MEC defende reformas para reduzir evasão em faculdades. Disponível em: <http://www.brasil.gov.br/educacao/2016/10/mecdefendereformas-para-reduzir-evasao-em-faculdades $>$. Acesso em: 17 abr. 2017.

BRASIL. Lei ${ }^{\circ}$ 11.096, de 13 de janeiro de 2005. Institui o Programa Universidade para Todos - PROUNI, regula a atuação de entidades beneficentes de assistência social no ensino superior; altera a Lei no 10.891, de 9 de julho de 2004, e dá outras providências. Diário Oficial da União, Brasília, DF, 14 jan. 2005c. Disponível em: http://goo.gl/jBkn0e. Acesso em: 05 jun. 2011.

BRASIL. IBGE. Pesquisa Nacional por Amostra de Domicílio (PNAD), 2013. Disponível em: 〈http://www.ibge.gov.br>. Acesso em: 18 ago. 2016. 
BRASIL. Lei n. ${ }^{\circ}$ 12.711, de 29 de agosto de 2012. Dispõe sobre o ingresso nas universidades federais e nas instituições federais de ensino técnico de nível médio e dá outras providências. Diário Oficial [da] República Federativa do Brasil, Poder Executivo, Brasília, DF, 30 ago. 2012b. Disponível em: <http://www.planalto.gov. br/ccivil_03/_ato20112014/2012/lei/112711.htm>. Acesso em: 18 ago. 2016.

BRASIL. Lei $n .^{\circ}$ 10.260, de 12 de julho de 2001. Dispõe sobre o Fundo de Financiamento ao estudante do ensino superior e dá outras providências. Disponível em: <http://www.planalto.gov.br/ccivil_03/leis/LEIS_2001/L10260. htm>. Acesso em: 09 mar. 2017.

BRASIL. Decreto $\mathrm{n}^{\circ}$ 6.096, de 24 de abril de 2007. Institui o Programa de Apoio a Planos de

Reestruturação e Expansão das Universidades Federais - REUNI. Diário Oficial da União.

Brasília (DF), 25 abr. 2007. Disponível em: <http://www.planalto.gov.br/ccivil_03/_Ato20072010/2007/Decreto/D6096.htm>. Acesso em: 20 abr. 2017.

BRZEZINSKI, Iria. Tramitação e desdobramentos da LDB/1996: embates entre projetos antagônicos de sociedade e de educação. Trab. educ. saúde, Rio de Janeiro, v. 8, n. 2, p. 185-206, Out. 2010. Disponível em: <http://www.scielo.br/ scielo.php?script=sci_arttext\&pid=S198177462010000200002\&lng=en\&nrm= iso>. Acesso em: 13 jan. 2017.

CARVALHO, José Sérgio Fonseca de. "Democratização do ensino" revisitado. Educação e Pesquisa, São Paulo, v. 30, n. 2, p. 327-334, maio/ago. 2004.

CORBUCCI, Paulo Roberto. Dimensões estratégicas e limites do papel da educação para o desenvolvimento brasileiro. IPEA, Brasília, julho de 2007. p. 7-32.

COUTINHO, Carlos Nelson. Cidadania, Democracia e Educação. In: Escola: espaço de construção da cidadania. Série IDÉIAS, n. 24. São Paulo: Fundação para o Desenvolvimento da Educação (FDE), 1994. p. 13-26. 
CUNHA, Luiz Antônio. Ensino Superior e universidade no Brasil. In: LOPES, Eliane Marta Santos Teixeira; FARIA FILHO, Luciano Mendes de; VEIGA, Cynthia Greive. 500 anos de educação no Brasil. Belo Horizonte: Autêntica, 2000.

ESTRADA, Adrian Alvarez; RADAELLI, Andressa. A política de assistência estudantil em uma universidade pública: a perspectiva estudantil. Revista Eletrônica de Política e Gestão Educacional. UNESP, n. 16, $1^{\circ}$ semestre de 2014, p. 32-47.

GIL, Antonio Carlos. Como elaborar projetos de pesquisa. 4. ed. São Paulo: Atlas, 2002.

GISI, Maria Lourdes. A Educação Superior no Brasil e o caráter de desigualdade do acesso e da permanência. Diálogo Educacional, Curitiba, v. 6, n. 17, p. 97-112, 2006.

GISI, Maria Lourdes; HANHART, Siegfried; FILIPAK, Sirley Terezinha. As Políticas de Educação Superior e as Possibilidades da Democratização do Acesso. In: MIGUEL, Maria Elisabeth Blanck; FERREIRA, Jacques de Lima. (OrgS.). Formação de Professores: História, Políticas Educacionais e Práticas Pedagógicas. 1. ed. Curitiba: Editora Appris, 2015. p. 105-128.

GISI, Maria Lourdes; PEGORINI, Diana Gurgel. As Políticas de Acesso e Permanência na Educação Superior: A Busca da Igualdade de Resultados. Política e Gestão Educacional (Online), v. 20, p. 21-37, 2016.

LIMA, Kátia. Reforma da universidade no governo Lula: o relançamento do conceito de público não-estatal. In: NEVES, Lucia. (Org.). A reforma universitária do governo Lula: reflexões para o debate. São Paulo: Xamã, 2004. p. 23-46.

MOROSINI, Marília Costa; CASARTELLI, Alam de Oliveira; SILVA, Ana Cristina Benso; SANTOS, Betina Steren; SCHMITT, Rafael Eduardo; GESSINGER, Rossana Maria. A evasão na educação superior no Brasil: uma análise da produção de conhecimento nos periódicos Qualis entre 2000-2011. Disponível em: <http://www.alfaguia.org/>. Acesso em: 23 jul. 2017.

MUNIZ, Regina Maria Fonseca. O direito à Educação. Rio de Janeiro: Renovar, 2002. 
OLIVEIRA, João Ferreira de; BITTAR, Mariluce. Ensino Superior noturno no Brasil: democratização do acesso, da permanência e da qualidade. In: CONGRESSO IBERO-BRASILEIRO DE POLÍTICA E ADMINISTRAÇÃO DA EDUCAÇÃO, 1., CONGRESSO LUSO-BRASILEIRO DE POLÍTICA E ADMINISTRAÇÃO DA EDUCAÇÃO, 6., CONGRESSO DO FÓRUM PORTUGUÊS DE ADMINISTRAÇÃO EDUCACIONAL, 4.,. Portugal/Espanha, Anais... São Paulo: Anpae, 2010. Disponível em: <www.anpae.org.br/iberolusobrasileiro2010/cdrom/52.pdf〉. Acesso em: 11 abr. 2017.

RISTOFF, Dilvo Ilvo. O novo perfil do campus brasileiro: uma análise do perfil socioeconômico do estudante de graduação. Avaliação, Campinas; Sorocaba, SP, v. 19, n. 3, p. 723-747, nov. 2014.

ROSA, Chaiane de Medeiros. Limites da democratização da educação superior: entraves na permanência e a evasão na Universidade Federal de Goiás. In: Poíesis Pedagógica, Catalão (GO), v. 12, n. 1, p. 240-257, jan/jun. 2014. Disponível em: <https://revistas.ufg.emnuvens.com.br/poiesis/article/download/31219/16813>. Acesso em: 26 abr. 2017.

SANTOS, Antonio Raimundo dos. Metodologia científica: a construção do conhecimento. 4. ed. Rio de Janeiro: DP\&A, 2000.

SANTOS, Georgina Gonçalves dos; SILVA, Lélia Custódio da. A evasão na educação superior: entre debate social e objeto de pesquisa. In: SAMPAIO, Sônia Maria Rocha (Org.). Observatório da vida estudantil: primeiros estudos [online]. Salvador: EDUFBA, 2011, pp. 249-262. Disponível em: <http://static.scielo.org/ scielobooks/n656x/pdf/sampaio9788523212117.pdf〉. Acesso em: 20 jul. 2017.

SEVERINO, Antonio Joaquim. Expansão do ensino superior: contextos, desafios, possibilidades. In: Revista Avaliação, v. 14, n. 2. Campinas, 2009, p. 253-266, jul. Disponível em: 〈http://www.scielo.br/pdf/aval/v14n2/a02v14n2.pdf〉. Acesso em: 20 jul. 2017.

SGUISSARDI, Valdemar. Educação Superior no Brasil. Democratização ou massificação mercantil? Educ. Soc., Campinas, v. 36, n. 133, p. 867-889, dez. 2015. Disponível em <http://www.scielo.br/scielo.php?script=sci_arttext\&pid=S0101 73302015000400867\&lng=pt\&nrm=iso >. Acesso em: 07 dez. 2016. 
SILVA, Lauraci Dondé da; ZORZO, Cacilda Maria; SERAFIM, Márcia Ladeia. Evasão: Diagnóstico e Prevenção. In: GARRIDO, Susane Lopes; CUNHA, Maria Isabel da; MARTINI, Jussara Gue. Os rumos da educação superior. São Leopoldo: Universidade do Vale do Rio dos Sinos, 2002.

SILVA, Maria das Graças Martins da; VELOSO, Tereza Christina Mertens Aguiar. Acesso à educação superior: significados e tendências em curso. Série Estudos, Campo Grande, n. 30, p. 221-235, jul./dez. 2010.

SILVA JUNIOR, João dos Reis; SGUISSARDI, Valdemar. Novas faces da educação superior no Brasil: Reforma do Estado e mudança na produção. São Paulo: Cortez, USF/Ifan, 2001.

SINDICATO DAS MANTENEDORAS DE ENSINO SUPERIOR - SEMESP. Mapa do Ensino Superior no Brasil 2016. Disponível em: <http://convergenciacom.net/ pdf/mapa_ensino_superior_2016.pdf >. Acesso em: 17 abr. 2017.

ZAGO, Nadir. Do acesso à permanência no ensino superior: percursos de estudantes universitários de camadas populares. Rev. Bras. Educ., Rio de Janeiro, v. 11, n. 32, p. 226-237, ago. 2006. Disponível em: <http://www.scielo.br/scielo. php?script $=$ sci_arttext\&pid $=S 141324782006000200003 \& \operatorname{lng}=e n \& n r m=i s o>$. Acesso em: 20 jan. 2017.

ZAINKO, Maria Amélia Sabbag. Educação superior, democracia e desenvolvimento humano sustentável. In: ZAINKO, Maria Amélia Sabbag; GISI, Maria Lourdes. Políticas e gestão da educação superior. Curitiba: Champagnat, 2003. 266 p. (Coleção educação. Gestão e política; 2).

Recebido: 08/06/2017

Received: 06/08/2017

Aprovado: 04/07/2017

Approved: 07/04/2017 